\title{
Trends in Canadian respiratory clinical trials from 2001 to 2011
}

\author{
Claire Elizabeth Tacon PhD*, Hina Abbas HBSc MBt*, Shiyuan Zhang MSc, \\ Barbara Nicholls BSc, Glenn Crater MD, Zhen Su MD MBA
}

\begin{abstract}
CE Tacon, H Abbas, S Zhang, B Nicholls, G Crater, Z Su. Trends in Canadian respiratory clinical trials from 2001 to 2011. Can Respir J 2014;21(3):181-184.
\end{abstract}

Clinical research bridges patients' unmet medical need with innovative medicines, increases knowledge acquisition by clinicians, and creates solutions to improve the sustainability and quality of the Canadian health care system and economy. The Canadian Institutes of Health Research and the Canadian Lung Association have recently raised concerns over declining research activities within the Canadian respiratory community. While there are currently $>3000$ ongoing clinical trials in Canada, the number of trials investigating common respiratory diseases is unknown. The objective of the present study was to monitor the trends in industry- and nonindustry-sponsored respiratory clinical trials in Canada from 2001 to 2011. Trialtrove 2012 (Citeline, an Informa UK business), a database containing summarized clinical trial information regarding pharmaceutical products, was searched using common chronic respiratory disease terms: "allergic rhinitis", "asthma", "chronic obstructive pulmonary disease (COPD)", "cystic fibrosis", "respiratory infections", "pulmonary fibrosis" and "smoking cessation". Over the past 10 years, the number of respiratory clinical trials conducted in Canada has increased (4.49 per year; $\mathrm{P}=0.004$ ). From 2001 to 2011, the majority of trials were performed in asthma, followed closely by respiratory infections and COPD. Over the past decade, the number of trials investigating COPD and respiratory infections increased $(\mathrm{P}<0.05)$, while asthma trials showed a declining trend since 2007. Of the clinical trials performed during this 10 -year period, the majority were in phase III, with a significant increase in the number of phase II trials (2.49 per year; $\mathrm{P}=0.008)$. However, certain trends observed are concerning and warrant further monitoring in the coming years.

Key Words: Canada; Clinical trials; Respiratory

$\mathrm{R}$ espiratory diseases affect millions of Canadians, with prevalence rates projected to climb. It is expected that the number of individuals living with chronic obstructive pulmonary disease (COPD) in Canada will increase from one million in 2012 to an estimated 3.5 million in 2042 (1). Similarly, the prevalence of asthma in Canada is expected to increase from 4.4 million in 2012 to 5.9 million in 2024 (1). Respiratory diseases are the third most common reason for hospitalization and death (1), and have a significant economic impact on the Canadian health care system. In 2007, accounting for more than $6.0 \%$ of total health care costs, nearly $\$ 5.70$ billion in direct costs and $\$ 6.72$ billion in indirect costs were associated with respiratory disease (2). Therefore, there is significant need for accelerated novel medicine development for respiratory diseases in Canada.

Innovative medicines have the potential to improve patients' quality of life, reduce the morbidity associated with respiratory disease, prolong patients' lives and, as such, reduce the burden of disease on the health care system. The development of innovative medicines is long and inherently risky due to the high failure rate of drug development: for every 5000 to 10,000 compounds screened for the required biological activity, 250 enter into preclinical testing, of which only five are ever tested in humans (3). Clinical research is the most expensive

\section{Les tendances des essais cliniques en santé respiratoire au Canada entre 2001 et 2011}

La recherche clinique relie les besoins médicaux non satisfaits des patients aux médecines novatrices, accroît l'acquisition du savoir des cliniciens et crée des solutions pour améliorer la pérennité et la qualité du système et de l'économie de la santé au Canada. Les Instituts de recherche en santé du Canada et l'Association pulmonaire du Canada ont récemment exprimé leur préoccupation à l'égard de la diminution des activités de recherche au sein de la communauté de la santé respiratoire du Canada. Plus de 3000 essais cliniques sont en cours au Canada, mais on ne sait pas combien portent sur les maladies respiratoires fréquentes. La présente étude visait à surveiller les tendances des essais cliniques en santé respiratoire financés ou non par l'industrie au Canada entre 2001 et 2011. Les chercheurs ont fouillé Trialtrove 2012 (Citeline, une entreprise d'Informa au Royaume-Uni), une base de données contenant de l'information résumée sur les essais cliniques au sujet des produits pharmaceutiques, au moyen de termes courants liés aux maladies respiratoires chroniques : allergic rhinitis, asthma, chronic obstructive pulmonary disease (COPD), cystic fibrosis, respiratory infections, pulmonary fibrosis et smoking cessation. Depuis dix ans, le nombre d'essais cliniques en santé respiratoire menés au Canada a augmenté (4,49 par année; $\mathrm{P}=0,004)$. De 2001 à 2011, la majorité des essais a porté sur l'asthme, suivie de près par les infections respiratoires et la maladie pulmonaire obstructive chronique (MPOC). Depuis dix ans, le nombre d'essais sur la MPOC et les infections respiratoires a augmenté $(\mathrm{P}<0,05)$, tandis que les essais sur l'asthme ont connu une tendance à la baisse depuis 2007. Parmi les essais cliniques effectués pendant cette période de dix ans, la majorité était de phase III, et on constatait une augmentation importante du nombre d'essais de phase II (2,49 par année; $\mathrm{P}=0,008)$. Cependant, certaines tendances observées sont inquiétantes et justifient une surveillance supplémentaire au cours des prochaines années.

phase of drug development and consumes the majority of industry's research and development $(\mathrm{Rx} \& \mathrm{D})$ investment.

Clinical research facilitates patients' access to innovative medicines, improves health outcomes and increases knowledge acquisition by clinicians. Furthermore, the contribution of the innovative life sciences industry and its clinical trial research has a major impact on the local economy and health care system. The clinical trial research activities in respiratory disease also provide unique training opportunities and increase the global influence of Canadian respirologists.

As such, the clinical research landscape has become highly competitive in recent years (4). Much of the early stage clinical research approximately $62 \%$ of the international active trials in phase I and $42 \%$ of phase II active trials - is performed in the United States. In contrast, the majority of the active trials in phase III and IV $(37 \%$ and $38 \%$, respectively) are being conducted in Western Europe (4).

There are currently $>3000$ ongoing clinical trials in Canada, accounting for $5 \%$ to $7 \%$ (depending on the phase of development) of international active clinical trials. These clinical trials, however, have not been divided into therapy areas or diseases. Due to this paucity of information, it is difficult to evaluate the numbers and trends of clinical research associated with respiratory disease in Canada. As a

*Authors who contributed equally to the study GlaxoSmithKline Inc Canada, Mississauga, Ontario

Correspondence: Dr Claire Elizabeth Tacon, GlaxoSmithKline Inc Canada, 7333 Mississauga Road, Mississauga, Ontario L5N 6L4.

Telephone 905-819-3092, fax 905-819-3099, e-mail claire.e.tacon@gsk.com 


\section{TABLE 1}

Respiratory clinical trials in total over the 10-year period

\begin{tabular}{lcc}
\hline Type of trend analyzed & Trials, $\mathbf{n}$ & $\begin{array}{c}\text { Annual change in the } \\
\text { number of trials }(\mathbf{P})\end{array}$ \\
\hline Respiratory disease trials & 561 & $4.49(0.004)$ \\
Trials according to disease type & & \\
$\quad$ Allergic rhinitis & 82 & $0.63(0.05)$ \\
Asthma & 140 & $0.41(0.5)$ \\
Chronic obstructive pulmonary disease & 110 & $1.07(0.01)$ \\
Respiratory infections & 137 & $1.01(0.04)$ \\
Cystic fibrosis & 40 & $0.58(0.03)$ \\
Pulmonary fibrosis & 12 & $0.19(0.07)$ \\
$\quad$ Smoking cessation & 40 & $0.60(0.003)$ \\
Trials according to phase & & \\
Phase I & 37 & $0.21(0.2)$ \\
Phase II & 173 & $2.49(0.008)$ \\
Phase III & 224 & $0.85(0.2)$ \\
Phase IV & 124 & $0.95(0.05)$ \\
Trial according to sponsor type & & \\
Collaborative & 53 & $0.41(0.1)$ \\
Industry & 431 & $2.31(0.03)$ \\
Nonindustry & 102 & $1.61(0.002)$ \\
\hline
\end{tabular}

The trials are presented separately according to characteristics of the trial, including variables such as disease type, phase and trial sponsor. The annual change in the number of trials and the associated $P$ values were determined through linear regression

result, the Canadian respiratory research community lacks oversight at the national level with regard to its competitiveness in clinical research activities. Thus, we performed a research study to address this knowledge gap, the objective of which was to determine the trends in respiratory clinical trials in Canada from 2001 to 2011.

\section{METHODS}

Trialtrove 2012 (Citeline, an Informa UK business), a database containing summarized clinical trial information, was searched for trials conducted in Canada between 2001 and 2011 in the following disease types: allergic rhinitis, asthma, COPD, cystic fibrosis, respiratory infections, pulmonary fibrosis and smoking cessation. The Trialtrove dataset only includes trials investigating a marketed or developmental drug and does not include observational studies. Trialtrove was chosen because it had a large number of clinical trials in the database for most disease categories. Furthermore, the sources used by Trialtrove to populate the database are varied and include, but are not limited to, web sources (ClinicalTrials.gov, Cancer.gov, controlled trials UK, Centerwatch), company conference calls with analysts, securities and exchange commission filings, news feeds, press releases and medical meetings (5). Each trial is categorized based on disease type and disease type assignment is based on Trialtrove's 'Disease Scope Statement' for that disease.

Only trials designated as 'Open enrollment' (subject recruitment stage), 'Closed enrollment' (subject enrollment is complete, but trial is still ongoing), 'Completed enrollment' (trial is completed and primary endpoints have been reported) and 'Temporarily closed' (subject recruitment or enrollment has been suspended but may resume) were included in the search. Disease type was kept consistent with the category assigned in Trialtrove, but duplicate studies with the same protocol title, sponsor, phase and indication were removed. The designated therapy area in these cases was chosen from assessment of the primary objective of the trial. Only one study, including both asthmatic and COPD subjects, was included in both the 'asthma' and the 'COPD' therapy area and, as such, was counted twice. Studies only designated to be within the respiratory therapy area due to trial outcomes involving multiple organ systems were excluded. The dataset included industryand non-industry-sponsored trials.

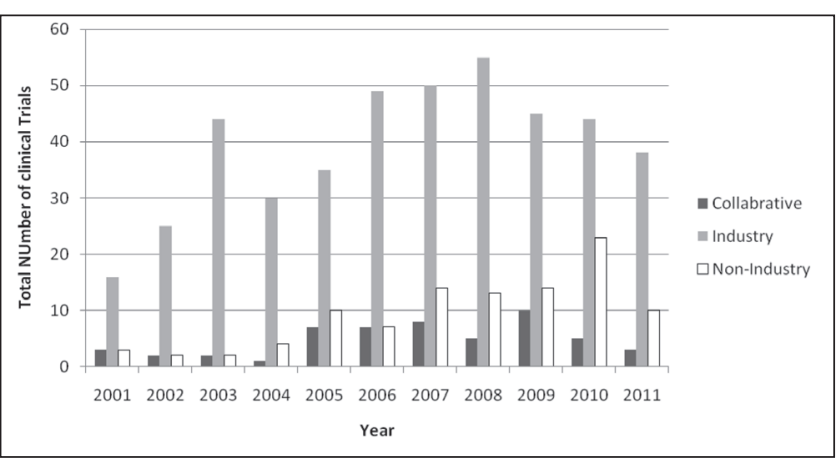

Figure 1) Total number of respiratory clinical trials conducted in Canada from 2001 to 2011

Trial phases were defined by Trialtrove as follows: Phase I - generally studies conducted in a small number of healthy volunteers, these studies are conducted to determine a drug's safety profile as well as its pharmacokinetic and/or pharmacodynamic profile; Phase I/II describes trials that are combination of phase I and II; Phase II - typically dose-ranging studies including a larger group of subjects that have the disease, disorder or addiction of interest. These trials evaluate safety and efficacy of the drug at a range of doses; Phase II/III describes trials that are combination of phases II and III; Phase III typically confirm the safety and efficacy of a drug at selected doses in a large group of patients. These studies may also compare the drug against the current 'gold standard' of treatment; Phase III/IV describes trials that are a combination of phases III and IV; Phase IV - are typically conducted after a drug is approved and marketed and evaluate the safety and effectiveness of the drug in large numbers of patients or in subpopulations. In the present article, the trials reported by Trialtrove as phase I/II were included with phase II trials, those reported as phase II/III were included with phase III trials and those reported as phase III/IV were included with phase IV trials.

The total number of respiratory trials were reported in whole numbers and summarized graphically. Several grouping variables, such as disease types, trial phase and trial sponsor type, were used to determine the number of trials with the specific categorization. To estimate the trend in the total number of trials conducted during the study period, linear regression was used to fit the number of trials to a linear model to determine the average annual growth in the number of trials. Additionally, linear regression was performed to determine the trial trends in each specific disease type, trial phase and trial sponsor type. The trends in the number of trials were described by change in number of trials per one year over the 10-year study period (Table 1), with its associated $\mathrm{P}$ value, with a null hypothesis of no change in the number of trials per year over the 10-year period. All statistical analyses were performed using Excel 2007 (Microsoft Corporation, USA).

\section{RESULTS}

Over the 10-year period, there were a total of 561 respiratory trials and the total number of trials conducted in Canada within the respiratory therapy area significantly increased by 4.49 per year $(\mathrm{P}=0.004)$ (Table 1). As shown in Figure 1, the total number of trials increased from 2001 and peaked in 2007, with 73 trials conducted in Canada during that year. A decrease in the total number of clinical trials was noted in 2011. During this 10 -year period, 82 trials were performed in allergic rhinitis (change of 0.63 per year; $P=0.05$ ), 140 in asthma (change of 0.41 per year; $\mathrm{P}=0.5$ ), 110 in COPD (change of 1.07 per year; $\mathrm{P}=0.01$ ), 137 in respiratory infections (change of 1.01 per year; $\mathrm{P}=0.04$ ), 40 in cystic fibrosis (change of 0.58 per year; $\mathrm{P}=0.03$ ), 40 in smoking cessation (change of 0.60 per year; $\mathrm{P}=0.003$ ) and 12 in pulmonary fibrosis (change of 0.19 per year; $\mathrm{P}=0.07$ ) (Figures $2 \mathrm{~A}$ and $2 \mathrm{~B}$, and Table 1 ). The number of asthma trials remained relatively constant from 2001 to 2004, after which the number of trials increased until 2007, with 25 trials performed in asthma that year. The number 


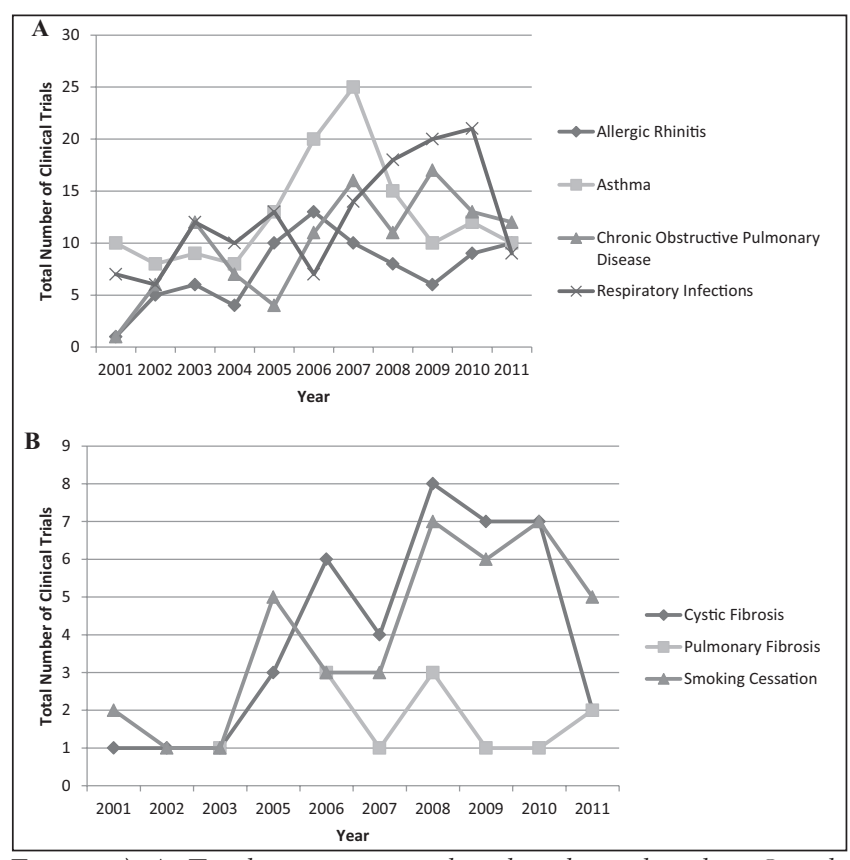

Figure 2) A Trend in respiratory clinical trials conducted in Canada according to disease from 2001 to 2011. Disease type is based on Trialtrove's (Citeline, an Informa UK business) 'Disease Scope Statement' for allergic rhinitis, asthma, chronic obstructive pulmonary disease and respiratory infections. B Trend in respiratory clinical trials conducted in Canada according to disease from 2001 to 2011. Disease type is based on Trialtrove's 'Disease Scope Statement' for cystic fibrosis, pulmonary fibrosis and smoking cessation

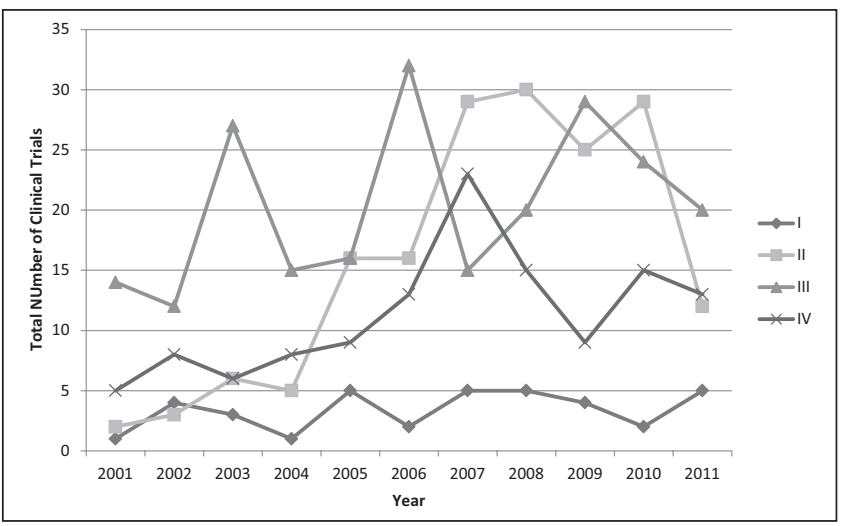

Figure 3) Respiratory clinical trials according to phase from 2001 to 2011. Phase I: Generally studies conducted in a small number of healthy volunteers. These studies are generally conducted to determine a drug's safety profile as well as its pharmacokinetic and/or pharmacodynamic profile; Phase II: Typically dose-ranging studies including a larger group of subjects who have the disease, disorder or addiction of interest. These trials evaluate safety and efficacy of the drug at a range of doses; Phase III: Typically confirm the safety and efficacy of a drug at selected doses in a large group of patients. These studies may also compare the drug against the current 'gold standard' of treatment; Phase IV: Typically conducted after drug is approved and marketed and evaluates the safety and effectiveness of the drug in large numbers of patients or in subpopulations. In the present article, the trials reported by Trialtrove (Citeline, an Informa UK business) as phase I/II were included with phase II trials, those reported as phase II/III were included with phase III and those reported as phase III/IV were included with phase IV trials

of asthma trials conducted in Canada has since declined over the past four years, with 10 trials performed in asthma in 2011. In contrast, the number of trials in COPD and respiratory infections have gradually increased over the 10-year period.

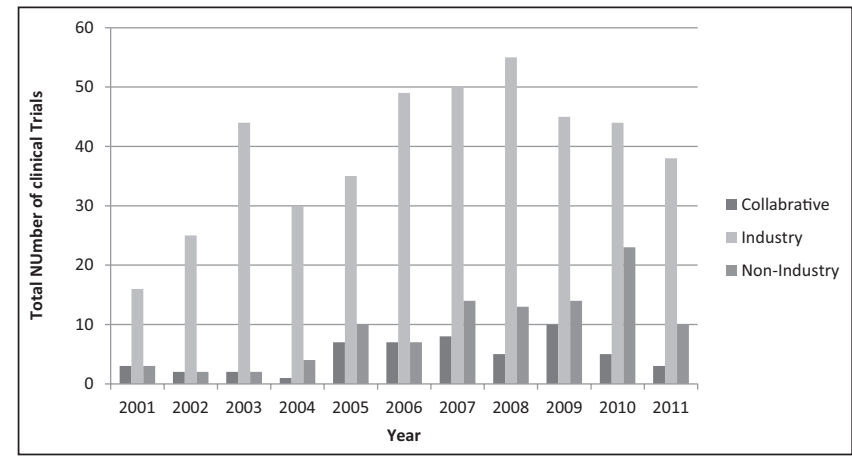

Figure 4) Respiratory clinical trial sponsors from 2001 to 2011. Nonindustry sponsors included government, not-for-profit or academic institutions. Collaborative sponsored trials included those sponsored by industry and nonindustry partners

\section{TABLE 2}

\section{Respiratory clinical trial sponsors according to year from} 2001 to 2011

\begin{tabular}{lccc}
\hline Year & Collaborative & Industry & Nonindustry \\
\hline 2001 & 3 & 16 & 3 \\
2002 & 2 & 25 & 2 \\
2003 & 2 & 44 & 2 \\
2004 & 1 & 30 & 4 \\
2005 & 7 & 35 & 10 \\
2006 & 7 & 49 & 7 \\
2007 & 8 & 50 & 14 \\
2008 & 5 & 55 & 13 \\
2009 & 10 & 45 & 14 \\
2010 & 5 & 44 & 23 \\
2011 & 3 & 38 & 10 \\
\hline
\end{tabular}

Data presented as $n$. Nonindustry sponsors included government, not-forprofit or academic institutions. Collaborative sponsored trials included those sponsored by industry and nonindustry partners

Over the 10-year period, 37 trials were designated as phase I, 173 were phase II, 224 were phase III and 124 were phase IV (Figure 3). Over the 10 -year period, phase I trials decreased by 0.21 per year $(\mathrm{P}=0.2)$, phase II trials significantly increased by 2.49 per year $(\mathrm{P}=0.008)$, phase III trials decreased by 0.85 per year $(\mathrm{P}=0.2)$ and phase IV trials significantly decreased by 0.95 per year $(\mathrm{P}=0.05)$ (Table 1$)$. Although an overall increase in phase II trials was noted, there was a sharp decline observed in the number of phase II trials in 2011.

The majority of trials had industry contribution either as sponsored or as collaborations, with a total of 431 trials sponsored between 2001 and 2011 (Figure 4, Table 2). Collaborative sponsored trials included those sponsored by industry and/or nonindustry partners, and accounted for 53 trials. Collaborative trials decreased by 0.41 per year $(\mathrm{P}=0.1)$, whereas industry-sponsored trials significantly increased by 2.31 per year $(\mathrm{P}=0.03)$ within this 10 -year period. Nonindustry sponsors included government, not-for-profit or academic institutions, which sponsored a total of 102 trials, increasing at 1.61 per year $(\mathrm{P}=0.002)$, within this 10-year period (Figure 4, Tables 1 and 2 ). There has been approximately a $30 \%$ decline in the number of industry-sponsored trials in Canada since 2008, whereas a general increase in the number of non-industrysponsored trials was noted from 2001 to 2010.

\section{DISCUSSION}

The global competiveness of clinical research has increased substantially in recent years, with more countries increasing capabilities and conforming to international standards to be selected for participation in clinical trial research (4). Despite reports of declining clinical trial research in Canada as a whole between 2006 and 2010 (6), our analysis 
of the respiratory clinical trials conducted in Canada from 2001 to 2011 indicates that there was a significant increase in the number of clinical trials within the respiratory field. During this period, there was a notable increase in clinical trials investigating COPD and respiratory infections as industry $R x \& D$ activities have significantly increased globally for these disease areas. This result can partially be explained by Canada's strong and growing research capabilities in COPD, where Canada ranks third, behind only the United States and United Kingdom based on an overall measure of citations, articles and citation per articles (7). Clinical trials investigating asthma, on the other hand, dramatically declined from 2007, which is concerning.

The majority of respiratory clinical trials conducted in Canada were in phase III. Phase II trials increased over the 10-year period; however, a sharp decline in phase II clinical trials was noted in 2011. It can be speculated that the reason for the phase II decline is partially due to many of the phase II programs concluding and the clinical development programs moving into phase III. However, this does not explain the gradual decline for phase III clinical trials in 2011. Nevertheless, there has been an increasing trend in respiratory clinical trials performed in Canada over the 10 years examined ( 4.49 per year; $\mathrm{P}=0.004)$. The data point toward a positive overall trend in phase II clinical trials $(\mathrm{P}=0.008)$, consistent with data presented by Leclerc et al (8), who observed a positive trend in phase II trials in Canada between 2005 and 2010, contrasting with a decreasing global trend over this five-year period. Finally, funding resource data clearly suggests that industry contribution and industry academic partnerships have played a critical role in respiratory medicine development over the past decade.

The value of clinical trials is highlighted in recent reports $(6,9)$ and action plans $(10,11)$, published by $R x \& D$, Canadian Institutes for Health Research and Association of Canadian Academic Healthcare Organizations, focusing on initiatives to assist in improving processes and, as such, attract more clinical trials to Canada. The recommendations include maintaining and continuing to build Canadian health care and research infrastructure and expertise, maintain ethical standards for human subject research but improve efficiency of ethics review, development of a national patient recruitment strategy and patient database, as well as implementing standard operating procedures and training at clinical trial sites countrywide $(10,11)$. It is hoped that these initiatives will assist in addressing some of the barriers and issues identified as potential explanations for the decreasing trend in clinical trial research in Canada (6).

There were several limitations to the present study. First, no formal quality assessments of the trials in the Trialtrove search results were performed. Second, although Trialtrove's clinical trials database is comprehensive, it is important to highlight that trial information is added as it is identified through various sources in the public domain and, therefore, may not include all clinical trials. In addition, the Trialtrove dataset only includes trials for marketed or pipeline drugs and does not include studies in which there is no drug intervention, retrospective studies or meta-analyses (5). Nonmedicinal clinical trials, such as trials investigating alternative strategies for disease management, are, therefore, not included in the dataset and, as such, the total number of trials, particularly those that are non-industrysponsored, may be under-represented. An additional limitation of the present study was that no a priori statistical plan was developed and the statistical analyses were performed on an ad hoc basis. To mitigate any selection bias on the analysis, all available data were modelled using linear regression and the trends in the 10-year study period are reported. Also, it should be noted that no formal comparison among the different types of trials was performed. Although such comparisons would be of great interest, they were beyond the scope of the present study. Despite these limitations, our study focused on the trend of respiratory clinical trials in Canada and will provide an important mechanism for the Canadian respiratory community to monitor its clinical research.

For the first time, our study provides important baseline data and enables future monitoring of the respiratory clinical research activities in Canada. We hope our approach will further assist the Canadian respiratory community to solidify its global leadership role in respiratory research and its mission to improve Canadian patient access to innovative respiratory medicines.

AUTHOR CONTRIBUTIONS: HA performed the search; CET, HA and SZ analyzed the data; CET and HA wrote the manuscript; SZ, BN, GC and ZS made substantial contributions to research design and/or the revision of the manuscript.

FUNDING: Provided by GlaxoSmithKline.

\section{REFERENCES}

1. Health Canada, CIHR, CLA, Statistics Canada. Respiratory Disease in Canada. <www.phac-aspc.gc.ca/publicat/rdc-mrc01/pdf/rdc0901e. pdf $>$ (Accessed November 13, 2012).

2. Public Health Agency of Canada. Life and Breath: Respiratory Disease in Canada. <www.phac-aspc.gc.ca/publicat/2007/lbrdcvsmrc/index-eng.php> (Accessed October 22, 2012).

3. Pharmaceutical Research and Manufacturers of America, Biopharmaceuticals in Perspective, Facts and Figures 2012 (Washington DC: PhRMA). <www.innovation.org/index.cfm/ ToolsandResources/Charts\#R\&D> (Accessed October 23, 2012).

4. SECOR \& KPMG. Improving the Health of Canadians. The contribution of the innovative pharmaceutical industry. <www. canadapharma.org/CMFiles/Our\%20Industry/Saving\%20Lives\%20 -\%20Transforming\%20Care/Improving_the_health_of_Canadians. pdf> (Accessed October 22, 2012).

5. Citeline ${ }^{\circledR}$, Trialtrove ${ }^{\circledR}$. Trialtrove ${ }^{\circledR}$ Online Training. <gsk.citeline. com/training/trainings.asp $>$ (Accessed October 3, 2012).

6. Rx\&D, CIHR, ACAHO. Canadian Clinical Trial Summit. Starting the Conversation. <www.canadapharma.org/CMFiles/Our\%20 Industry/Canadian\%20Clinical\%20Trial\%20Summit/ Backgrounder\%20Document/ClinicalTrialsSummit_Background_ Finalposting.pdf $>$ (Accessed June 17, 2013).

7. ScienceWatch.com by Thomson Reuters. Special Topics: Chronic Obstructive Pulmonary Disease (COPD): Top 20 Nations - Chronic Obstructive Pulmonary Disease (COPD). <http://archive. sciencewatch.com/ana/st/copd/nations> (Accessed March 20, 2013).

8. Leclerc JM, Laberge N, Marion J. Metrics of industry-sponsored clinical trials in Canada and comparator jurisdictions between 2005 and 2010. Healthcare Policy 2012;8:88-106.

9. Rx\&D, CIHR, ACAHO. Proceedings \& Implications from the 2011 Clinical Trials Summit. Towards an Action Plan. <www.canadapharma.org/CMFiles/Our\%20Industry/Canadian\%20 Clinical\%20Trial\%20Summit/ProceedingsFinal-

TowardsanActionPlan_March23.pdf> (Accessed June 17, 2013).

10. Rx\&D, CIHR, ACAHO. Towards Health \& Prosperity. An Update on an Action Plan to Help Attract More Clinical Trials to Canada. $<$ http://www.canadapharma.org/CMFiles/Our\%20Industry/ Canadian\%20Clinical\%20Trial\%20

Summit/2012CTSummitCommunique_EN.pdf>

(Accessed June 17, 2013).

11. Rx\&D, CIHR, ACA. An Action Plan to Help Attract More Clinical Trials to Canada. To Your Health \& Prosperity. $<$ www.canadapharma.org/CMFiles/Our\%20Industry/Canadian\%20 Clinical\%20Trial\%20Summit/ActionPlan_Final.pdf> (Accessed on June 17, 2013). 


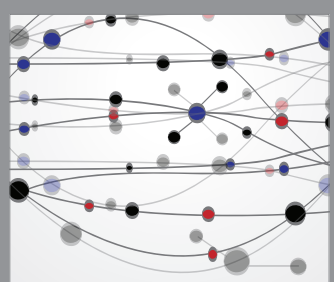

The Scientific World Journal
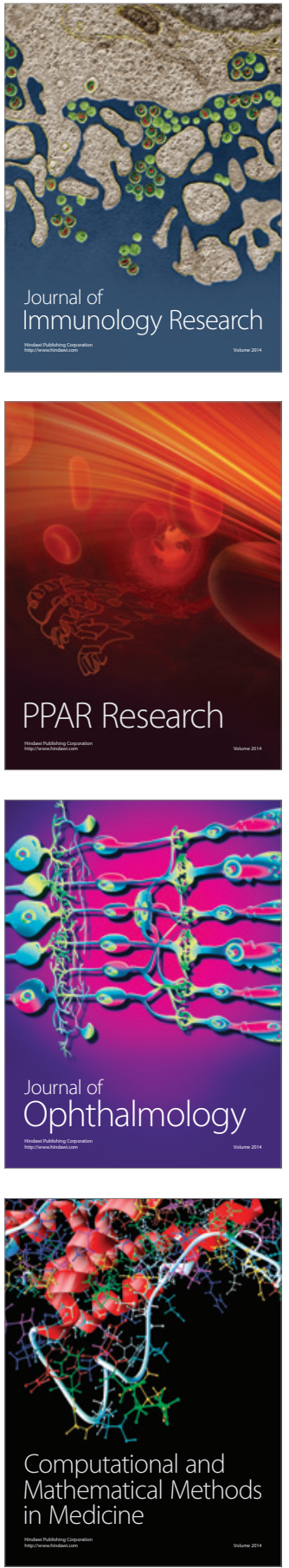

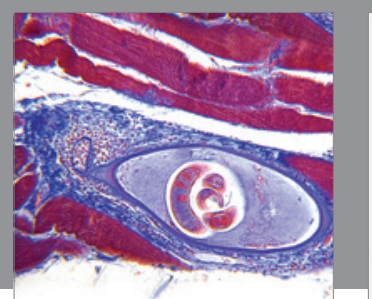

Gastroenterology Research and Practice

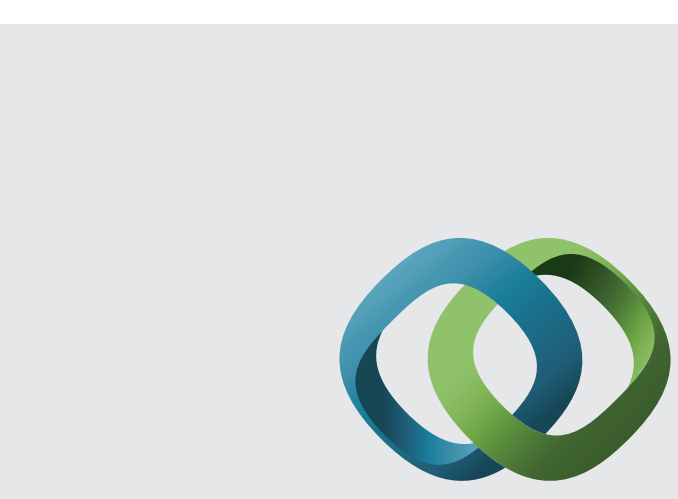

\section{Hindawi}

Submit your manuscripts at

http://www.hindawi.com
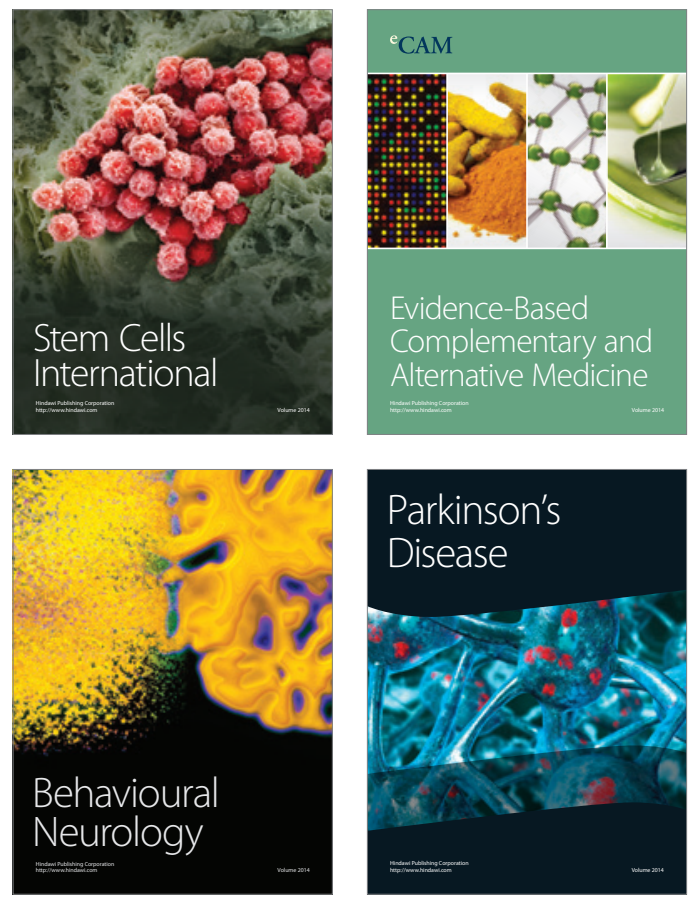
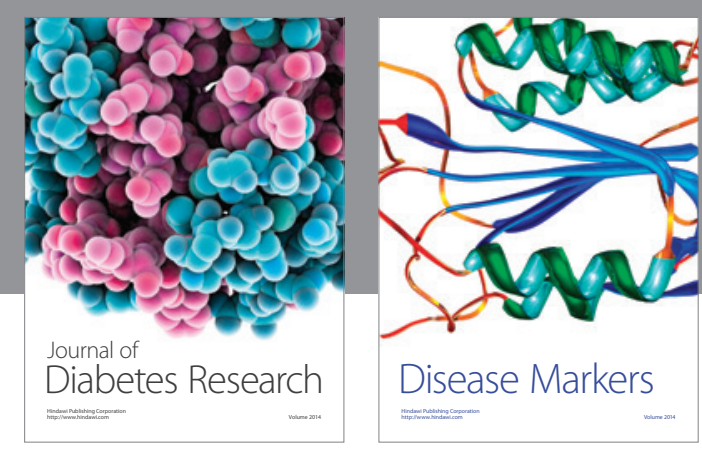

Disease Markers
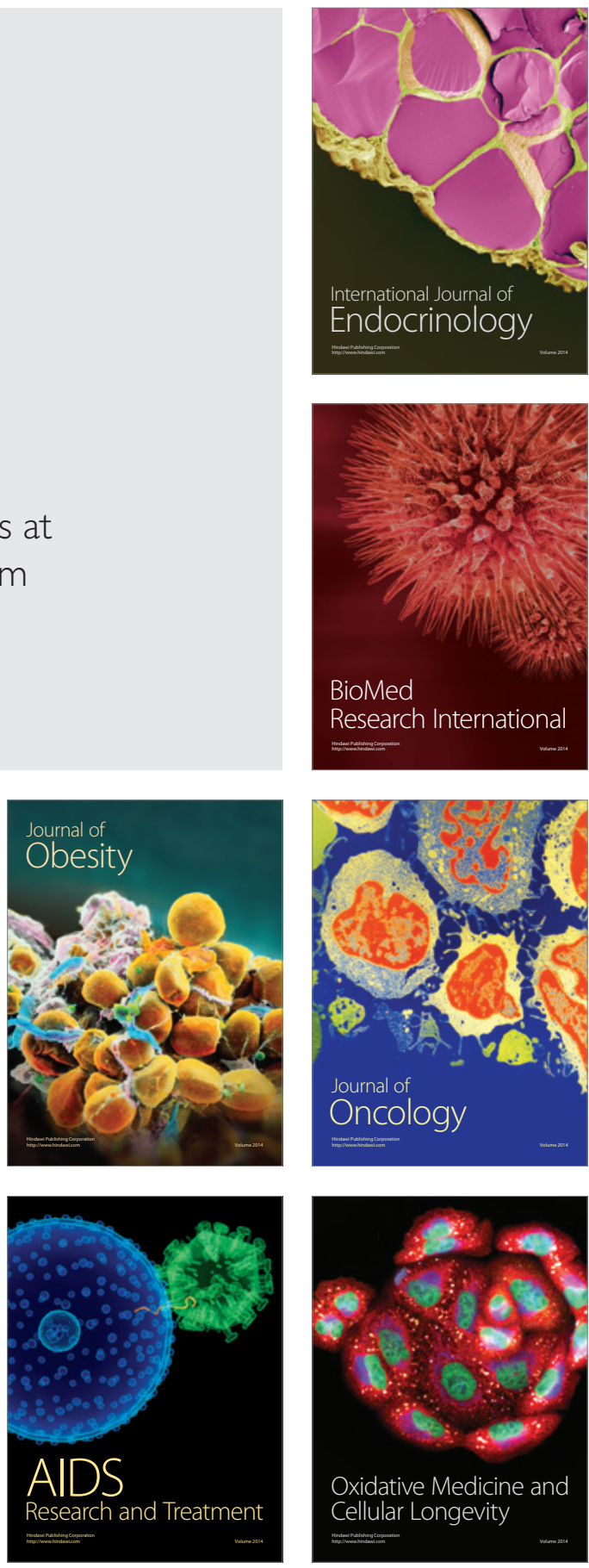